\title{
Bilateral papillitis with anti-neutrophil cytoplasmic antibodies associated with coeliac disease
}

\author{
D. Chan-Lam, V. Balasubramanian ${ }^{1}$ and R.B. Hogg
}

Departments of Haematology and ${ }^{1}$ Nephrology, Stobhill General Hospital, Glasgow G21 3UW, UK

\begin{abstract}
Summary: A 39 year old woman with untreated coeliac disease presented with some of its complications and bilateral papillitis. She was found to have antineutrophil cytoplasmic antibodies (ANCA) in high titres. Following institution of gluten-free diet the complications resolved. The papillitis, however, persisted and needed a course of prednisolone to resolve, and a fall in the ANCA titres was noted. We believe that this is the first report of an association of coeliac disease and ANCA.
\end{abstract}

\section{Introduction}

Coeliac disease is an autoimmune condition which affects primarily the gastrointestinal tract causing mucosal damage. ${ }^{1}$ Arthritis, ${ }^{2}$ cutaneous vasculitis ${ }^{3}$ and neurological disorders ${ }^{4}$ are recognized, though rare, complications of coeliac disease. Papillitis associated with coeliac disease has, however, to our knowledge not been previously reported. We report a case of coeliac disease complicated by arthritis, cutaneous vasculitis, secondary anaemia and papillitis with anti-neutrophil cytoplasmic antibodies (ANCA) in high titres.

\section{Case report}

A 39 year old woman was referred for investigation of anaemia and generalized tiredness. She was diagnosed as having coeliac disease at the age of 2 when she presented with recurrent diarrhoea. She was subsequently started on gluten-free diet until the age of 20 when it was discontinued. Examination revealed a small anaemic woman with no other positive findings. Investigations showed a haemoglobin of $77 \mathrm{~g} / \mathrm{l}$, white cell count $6.9 \times 10^{9} / 1$, with normal differential count, platelets $551 \times 10^{9} / 1$, ESR $90 \mathrm{~mm}$ in the first hour, reticulocytes $2 \%$, vitamin B12 $230 \mu \mathrm{g} / 1$ (normal more than 190), serum folate $2.4 \mu \mathrm{g} / 1$ (normal 1.9-14), red cell folate $360 \mathrm{ng} / \mathrm{l}$ (normal more than 100), ferritin $185 \mathrm{ng} / \mathrm{ml}$ (normal 14-30). Urea, electrolytes, liver function tests, thyroid function tests and urinalysis were normal. There was a diffuse increase in immunoglobulins on serum protein electro-

Correspondence: D. Chan-Lam, M.R.C.P. (UK) Accepted: 6 September 1990 phoresis. Chest X-ray was normal. Bone marrow examination showed highly reactive marrow with abundant iron but no ring sideroblasts.

In view of her past history, she had jejunal biopsy which showed subtotal villous atrophy with crypt hyperplasia consistent with the diagnosis of coeliae disease. She was started on gluten-free diet. Four months later she started complaining of arthralgic affecting the hands, knees and ankles. At the time she was also noted to have multiple purplish vasculitic skin macules affecting the anterior aspects of both legs. Immunoserology was negative for rheumatoid factor, anti-nuclear factor, mitochondrial and smooth muscle antibodies but strongly positive with a titre of $1 / 640$ for antineutrophil cytoplasmic antibodies (cytoplasmic staining). X-rays of hands and ankles showed no specific changes. Skin biopsy was not performed. Over the next 2 weeks she started complaining of difficulty in seeing clearly. Fundal examination revealed bilateral loss of disc margins. Perimetry showed a central scotoma and fluorescein angiography confirmed presence of bilateral papillitis Cerebrospinal fluid examination, computed tomographic scan and magnetic resonance imaging of the brain were essentially normal but visual evoked response showed delayed conduction in both pathways. There was no evidence of involvement of sinuses, chest or kidneys. At that time she admitted non-compliance to her diet.

Following institution of gluten-free diet, the skin lesions and arthralgia promptly improved and her haemoglobin rose to $119 \mathrm{~g} / \mathrm{l}$. The visual symptoms however showed no improvement. She was given prednisolone $60 \mathrm{mg}$ daily and in 2 months visual symptoms disappeared and fundal changes showed complete resolution. Her visual symptoms relapsed 
within a month of stopping steroids. She was started on a further course of prednisolone and 18 months later she remained well on a maintenance dose of $10 \mathrm{mg}$ daily of prednisolone. Repeat biopsy while on gluten-free diet showed normal duodenal and jejunal mucosa. Arthritis, cutaneous vasculitis and anaemia showed no evidence of reactivation. ANCA remains positive but with a reduced titre at $1 / 20$.

\section{Discussion}

The systemic manifestations of coeliac disease are well documented. In addition, there are reports of arthritis ${ }^{2}$ and cutaneous vasculitis ${ }^{3}$ resolving with institution of gluten-free diet. The failure of papillitis to resolve, in our patient, with gluten-free diet and prompt improvement with prednisolone suggests that her papillitis was due to a process independent of coeliac disease. With a positive ANCA, it would appear to be related to an associated autoimmune vasculitis of the optic discs. ANCA is a valuable immunoserological test for some vasculitides and high titres are usually found in active Wegener's granulomatosis. ${ }^{5}$ This patient has, as yet, no positive physical findings to suggest the development of Wegener's granulomatosis which is not known to present with isolated bilateral papillitis. ${ }^{6}$ Finally, the presence of ANCA in high titres in a patient with coeliac disease reinforces the association of cóeliac disease with other autoimmune diseases. ${ }^{7}$ Any direct link between ANCA and coeliac disease and aetiological role of ANCA in vasculitis remain to be seen.

\section{References}

1. Clark, M.L. Coeliac disease. In: Bouchier, I.A.D., Allen, A.N., Hodgson, H.T.S. \& Keighley, M.R.B. (eds) Textbook of Gastroenterology. Ballière Tindall, London, 1985, pp. 448-462.

2. Bourne, J.T., Kumar, P., Huskisson, E.C. et al. Arthritis and coeliac disease. Ann Rheum Dis 1985, 44: 592-598.

3. Meyers, S., Dikman, S., Spiera, H. et al. Cutaneous vasculitis complicating coeliac disease. Gut 1981, 22: 61-64.

4. Morris, J.S., Ajdukietricz, A.B. \& Reid, A.E. Neurological disorders and adult coeliac disease. Gut 1970, 11: 549-555.

5. Noelle, B., Specks, U., Lindemann, J. et al. Anticytoplasmic auto-antibodies: their immunodiagnostic value in Wegener granulomatosis. Ann Intern Med 1989, 111: $28-40$.

6. Fauci, A.S. Wegener's granulomatosis. In: Wyngaarden, J.B. \& Smith, L.H. (eds) Cecil Textbook of Medicine. J.B. Saunders, Philadelphia, 1985, pp 1943-1945.

7. Scott, B.B. \& Losowsky, M.S. Coeliac disease: a cause of various associated diseases? Lancet 1975, ii: 956-957. 